\title{
Comparison of Pulmonary Neutrophils in the Adult and Neonatal Rat after Hyperoxia
}

\author{
SUSAN E. KEENEY, MARY J. MATHEWS, ABIDA K. HAQUE, AND FRANK C. SCHMALSTIEG \\ Departments of Pediatrics, Pathology and Human Biological Chemistry and Genetics, The University of \\ Texas Medical Branch, Galveston, Texas 77555
}

\begin{abstract}
ABST
The mechanisms of the increased tolerance to hyperoxia of
neonatal animals of many species is incompletely understood. To
investigate the etiology of this difference we compared neutro-
phil entry into the lungs of neonatal and adult rats after hyperoxic
exposure. Adult rats were studied after exposure to $\geq 98 \% \mathrm{O}_{2}$ for
$60 \mathrm{~h}$ and neonatal rats after 3 and $7 \mathrm{~d}$. Neonatal survival was
prolonged compared with that reported for adult rats $(77 \%$ after
$7 \mathrm{~d}$ of exposure). In adult rats, there were significant increases in
pulmonary neutrophils after $60 \mathrm{~h}$ of $\mathrm{O}_{2}$ exposure. In neonatal
rats, these changes were not evident after $72 \mathrm{~h}$ of exposure, but
pulmonary neutrophils increased after $7 \mathrm{~d}$ of hyperoxia. Before
mortality, pulmonary neutrophils were distributed differently in
the age groups. After $7 \mathrm{~d}$ of $\mathrm{O}_{2}$ exposure in the neonates, total
neutrophil counts in lung tissue $\left(21.92 \pm 7.29\right.$ per $\mathrm{cm}^{2}$ grid) and
\end{abstract}
The mechanisms of prolonged neonatal tolerance to hyperoxia, which has been noted in the young of many species (1-3), are not completely understood. Species such as the rat, mouse, and rabbit, whose neonates exhibit tolerance, also demonstrate greater induction of antioxidant enzymes than adults in response to hyperoxia $(1,3)$. This enzyme increase is not seen in the guinea pig and hamster, whose neonates do not exhibit tolerance $(1,3)$. However, tolerance could also be related to a lower risk of hyperoxic cellular injury to the neonatal lung as a result of diminished oxygen free radical release, a hypothesis which has not been extensively investigated. Ischiropoulos et al. (4) showed lower subcellular superoxide generating capacity in response to $\mathrm{O}_{2}$ in neonatal rats compared with adults. Although the rate of generation of cellular reactive $\mathrm{O}_{2}$ species increases after hyperoxia $(5,6)$, neutrophil accumulation would be expected to augment the total oxidant load presented to pulmonary cells. Neutrophils accumulate in the lung after hyperoxic exposure $(7,8)$, where they may produce localized damage due to release of toxic oxygen radicals, arachidonic acid metabolites and proteases $(9,10)$.

Received April 4, 1994; accepted June 27, 1995.

Correspondence: Susan E. Keeney, M.D., Division of Neonatology, Route 0526, University of Texas Medical Branch, Galveston, TX 77555.

Supported by a Child Health Research Center Grant (HD 27841 Center Grant) from the National Institutes of Child Health and Human Development and R01-AI 23521 from the National Institute of Allergy and Infectious Diseases. lung myeloperoxidase $(0.085 \pm 0.02 \mathrm{U} / \mathrm{mg}$ protein $)$ remained significantly lower than in adults after $60 \mathrm{~h}$ of $\mathrm{O}_{2}$ exposure $(41.44$ \pm 9.08 per $\mathrm{cm}^{2}$ grid and $0.411 \pm 0.085 \mathrm{U} / \mathrm{mg}$ protein, respectively). However, in histologic specimens, $\mathrm{O}_{2}$-exposed neonates had higher percentages of neutrophils free in the alveolar air space than did adults, corresponding to a trend toward higher neutrophil counts in bronchoalveolar lavage fluid in the neonates. It appears that, in addition to delay in neutrophil influx into the lung, neonatal rats have lowered retention of neutrophils to the alveolar tissue. (Pediatr Res 38: 857-863, 1995)
MPO, myeloperoxidase
Abbreviations
BALF, bronchoalveolar lavage fluid

It is controversial whether neutrophil-mediated responses are necessary for production of acute hyperoxic lung injury. Data implicating neutrophils in the etiology of acute pulmonary oxygen toxicity include neutrophil depletion studies in rabbits, mice, and sheep (11-13) and studies correlating diminished inflammatory response with protection from $\mathrm{O}_{2}$-induced lung injury in the rat, baboon, and human $(8,14,15)$. However, other investigators have demonstrated, using similar species, that neutrophil depletion does not prevent $\mathrm{O}_{2}$-induced lung injury in several animal models, including the rabbit, sheep, mouse, and rat $(13,16-18)$. It is possible that the response depends on the agent used to deplete neutrophils (13).

Because neonates are known to have a diminished ability to mount a neutrophil response compared with adults (19), we hypothesized that neutrophil adherence and migration into neonatal lungs during hyperoxic exposure would be lower than in adults. To compare neutrophil entry into the lungs of adult and neonatal rats after hyperoxic exposure, we examined MPO activity in lung homogenates and neutrophil counts in BALF and histologic specimens before onset of mortality after hyperoxic exposure.

\section{METHODS}

Animals. Adult male Sprague-Dawley rats weighing 250$300 \mathrm{~g}(60-75 \mathrm{~d})$ were obtained from Harlan Sprague-Dawley, 
Indianapolis, IN. Timed-gestation pregnant female SpragueDawley rats were obtained from Sasco, Inc., Omaha, NE, and were allowed to spontaneously deliver at term. Neonates from two to four litters were pooled and divided between oxygen and air exposure groups. Analyses reffect the results from two to three separate exposures of neonatal animals and three separate exposures of adults.

Oxygen Exposures. Exposures to oxygen were performed in airtight plastic cages as previously described (20). Oxygen was humidified, provided at a flow rate of $5.0 \mathrm{~L} / \mathrm{min}$, and continuously analyzed. Oxygen concentration remained at $\geq 98 \%$ at all times. Animals were maintained in an exposure room with 12-h light-dark cycles. Adult rats were killed after exposure to $\mathrm{O}_{2}$ for $60 \mathrm{~h}$; pulmonary studies of neonates were performed after 3 and $7 \mathrm{~d}$ of $\mathrm{O}_{2}$ exposure. The exposure durations of 60 $h$ in the adults and $7 \mathrm{~d}$ in the neonates were chosen because we had previously demonstrated that, at these times, onset of mortality was imminent in the $\mathrm{O}_{2}$-exposed groups. We wished to compare these groups after each had experienced lung injury, when neutrophil influx could be expected to have occurred.

Survival was examined for 10 and $14 \mathrm{~d}$ in two additional neonatal exposure groups. For neonatal studies, cages were opened every $24 \mathrm{~h}$ to switch mothers between air and oxygen cages to minimize $\mathrm{O}_{2}$ toxicity to the mothers. All experiments were performed with the approval of the Animal Care and Use Committee of the University of Texas Medical Branch.

Animal Surgery and Preparation of Lung Homogenates. After exposure, the animals were anesthetized with sodium pentobarbital, $60-75 \mathrm{mg} / \mathrm{kg}$ intraperitoneally. A tracheostomy was performed, and the lungs were lavaged with $8 \mathrm{~mL}$ of $0.9 \%$ $\mathrm{NaCl}$ (saline) in adults and with $0.7 \mathrm{~mL}$ of saline in neonates (approximately $35 \mathrm{~mL} / \mathrm{kg}$ of body weight). The lavage volume was reinstilled for a total of five instillations. The remaining cell pellet was resuspended in hexadecyltrimethyl ammonium bromide buffer for MPO assay. Cell counts, and estimations of percent neutrophils in BALF were made with a hemocytometer. Neutrophils were identified as multinucleated cells slightly larger than lymphocytes and much smaller than the predominant macrophages in lavage specimens. Cytospin differential counts were not performed because determinations of MPO in the lavage cell pellet required all available material. MPO in the lavage cell pellet was used to corroborate neutrophil counts in lavage fluid. Bronchoalveolar lavages were not performed in 3-d-old neonates due to their small size. After lavage, the lungs were perfused free of blood via the pulmonary artery with ice-cold PBS. After perfusion, the lungs were dissected from large airways, weighed, and frozen in liquid nitrogen until homogenization. Therefore, lavage MPO and tissue MPO were measured from the same lungs.

Blood was obtained by cardiac puncture before lavage. Total neutrophil counts were performed using a hemocytometer after lysing of red blood cells with $1 \%$ acetic acid. Blood was obtained concurrently in the adult groups, but a separate exposure was performed to obtain blood in the 7-d-old neonates.

Histologic studies were performed in different animals than those used for lung biochemical studies to evaluate neutrophils in lungs without prior lavage. Animals were randomly selected from each exposure group for morphologic studies. The right lung was fixed for $\geq 24 \mathrm{~h}$ by tracheal instillation of $10 \%$ formalin at a pressure of $22 \mathrm{~cm}$ water for adults and $12-15 \mathrm{~cm}$ water for 7 -d-old neonates. The lower inflation for neonatal animals was chosen because this pressure adequately distended all lobes of the lung by inspection. We were concerned that higher pressures might result in overdistention or rupture of fragile neonatal lung tissue. In 3-d-old neonates, the lung was not inflated with formalin due to the technical difficulty of tracheostomy. Sections from the right upper and lower lobes were embedded in paraffin, cut at $4-\mu \mathrm{m}$ thickness, and stained with hematoxylin-eosin. Initial assessment was made of septal thickening and cellularity, alveolar edema, and intraalveolar hemorrhage by a blinded investigator. Another blinded investigator coded the slides for interstitial and intraalveolar edema and hemorrhage using a scale of $0-4(0=$ normal, $1=$ very mild, $2=$ mild to moderate, $3=$ moderate, $4=$ severe). Enumeration of neutrophils was performed in a $1-\mathrm{cm}^{2}$ grid at magnification $\times 400$ using an eyepiece micrometer disk. Neutrophils were identified as cells with multilobed nuclei exhibiting lighter-red nuclear staining than surrounding cells. Thirty randomly chosen grids from each animal were counted, 15 each from the upper and lower lobes of adults and 7-d-old neonates. The investigator was blinded as to treatment group. Ten grids were counted from 3-d-old neonates due to the small volume of tissue. Because the lungs from 3-d-old neonates were not inflated with formalin, more alveoli may have been included per grid. Although it should not cause differences between air and $\mathrm{O}_{2}$ groups in the 3-d-old animals, this could artifactually inflate the neutrophil counts per grid in the 3-d-old neonates compared with the lungs of 7-d-old neonates and adults. Neutrophils which were free within the alveolar air space and not attached to the interalveolar septum were counted and expressed as a percentage of the total count. Neutrophils within small vessels were not counted.

MPO assay. Alveolar lavage MPO was performed on the same lungs as tissue MPO. For measurement of MPO, lung tissue $(100-200 \mathrm{mg}$ ) was suspended in 5 volumes (wt/vol) of $0.5 \%$ hexadecyltrimethyl ammonium bromide in $50 \mathrm{mM}$ phosphate buffer, $\mathrm{pH}$ 6.0. The tissue was homogenized for $45 \mathrm{~s}$ and sonicated on ice for $60 \mathrm{~s}$. After centrifugation at $9000 \times g$, the supernatant was collected, and the cell pellet was reextracted for a total of four extractions (21). The supernatants were combined for measurement of MPO and protein. Only one extraction was required for release of MPO from granules in BALF. Measurement of MPO was performed by the method of Krawisz et al. (22) by measuring degradation of $\mathrm{H}_{2} \mathrm{O}_{2}$ in the presence of $o$-dianisidine hydrochloride and $0.0005 \% \mathrm{H}_{2} \mathrm{O}_{2}$. One unit of MPO was defined as that degrading $1 \mu \mathrm{mol}$ of peroxide per min at $25^{\circ} \mathrm{C}$. Protein in lung tissue and lavage fluid was measured using a bicinchoninic acid protein assay kit (BCA, Pierce, Rockford, IL) (23).

Statistical analysis. The number of adult rat samples was four for each air and $\mathrm{O}_{2}$ group for lung MPO activities and BALF measurements. The number was three for each group for histologic studies. The number of neonatal samples was 12 for each group of lung MPO, eight for each group of BALF measurements, and four for each neonatal group of histologic 
specimens. Data are expressed as mean \pm SEM unless otherwise specified. Analysis of neutrophil percentage in histologic specimens and edema and hemorrhage in histologic specimens are expressed as mean $\pm \mathrm{SD}$. Probabilities of differences between groups were estimated using one-way analysis of variance with Newman-Keuls testing of group comparisons. Comparisons of nonparametric data were made using a MannWhitney test. Correlations were made of measurements within each animal using a Pearson's test. Differences between groups of $p<0.05$ were considered to be statistically significant.

\section{RESULTS}

Mortality. Mortality was not examined in adult rats because mortality in this group has been reported by a number of investigators. Mortality after hyperoxic exposure of adult male Sprague-Dawley rats has been reported to be $>50 \%$ after $67 \mathrm{~h}$ of exposure (1), with less than $25 \%$ of adult rats surviving after $72 \mathrm{~h}$ of hyperoxic exposure (2). In animals exposed to $\mathrm{O}_{2}$ in our laboratory, the mortality rate was $22 \%$ at $60 \mathrm{~h}$. Respiratory distress existed in all animals. Survival of neonatal rats in $\mathrm{O}_{2}$ was $100 \%$ through $5 \mathrm{~d}$ of age, and dropped to $94 \%$ at $6 \mathrm{~d}$ $(45 / 48)$ and $77.1 \%$ after $7 \mathrm{~d}$ of $\mathrm{O}_{2}$ exposure (37/48). In the smaller group of neonatal rats (pooled from four litters) which were examined for $14 \mathrm{~d}$ and not killed at $7 \mathrm{~d}$ for pulmonary studies, survival dropped to $58 \%$ at $10 \mathrm{~d}(11 / 19)$ and $9.1 \%$ at $14 \mathrm{~d}(1 / 11)$.

Lung weights and body growth. Adult rats lost weight (mean $11.5 \mathrm{~g}$ ) after $60 \mathrm{~h}$ of $\geq 98 \% \mathrm{O}_{2}$ exposure, whereas those in air gained weight (mean $9.9 \mathrm{~g}$ ). All neonatal rats continued to gain weight throughout the exposure period (Table 1). After $3 \mathrm{~d}$, there were no differences in body weight and weight gain between the neonatal exposure groups. However, body weight and weight gain after $7 \mathrm{~d}$ of $\mathrm{O}_{2}$ exposure were significantly lower than in air-exposed neonatal rats (Table 1).

Lung weights of adult rats were higher in $\mathrm{O}_{2}$-exposed $(3.51$ $\pm 0.7 \mathrm{~g})$ compared with air-exposed rats $(2.06 \pm 0.19 \mathrm{~g})(p<$ $0.05)$. In addition, protein in the supernatant of BALF was significantly higher in $\mathrm{O}_{2}$-exposed adult rats $(p<0.01$; Fig. 1$)$. In neonates, lung weights after $3 \mathrm{~d}$ of $\mathrm{O}_{2}$ exposure did not differ from air controls (Table 1). Lung weights were lower after $7 \mathrm{~d}$ of $\mathrm{O}_{2}$ exposure compared with air, but lung weight measured as a percent of body weight did not differ between the exposure groups. Similarly to adults, BALF protein was increased significantly in neonatal rats exposed to $\mathrm{O}_{2}$ for $7 \mathrm{~d}$ ( $p<0.01$; Fig. 1). However, BALF protein was lower in the neonates after 7 $\mathrm{d}$ of $\mathrm{O}_{2}$ exposure than adults after $60 \mathrm{~h}$ of $\mathrm{O}_{2}(p<0.05)$. Because lung growth was impaired in neonatal rats exposed to

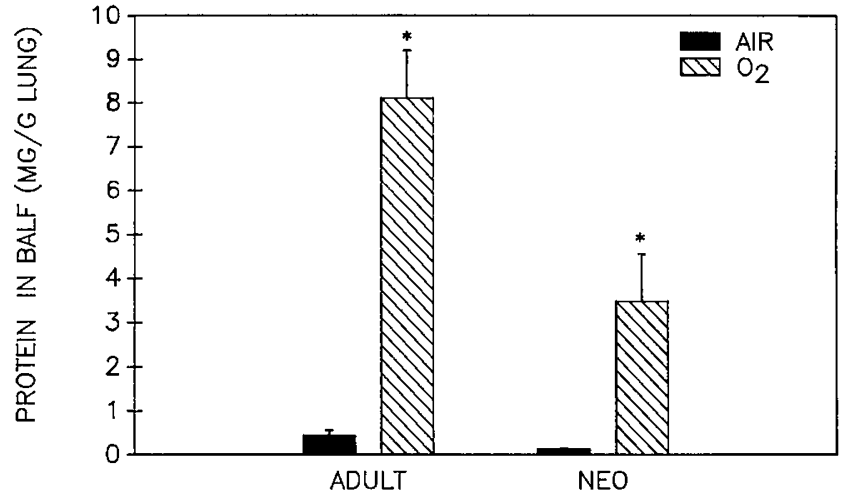

Figure 1. Total protein (mg/g lung tissue) in supernatant of BALF after exposure of adults for $60 \mathrm{~h}(A D U L T)$ or neonates for $7 \mathrm{~d}(N E O)$ to air (filled bars) or $\geq 98 \% \mathrm{O}_{2}$ (hatched bars). Data are expressed as mean $\pm \mathrm{SEM} ; * p<$ 0:01 for air $y s \mathrm{O}_{2}$ exposure, $n=4$ for adult groups, $n=8$ for neonatal groups. In the $\mathrm{O}_{2}$ exposure groups, adults had higher protein than neonates $(p<0.05)$.

$\mathrm{O}_{2}$, the measurement of lung weight as an indicator of edema was considered to be of little use. Pleural fluid was present in all adult rats exposed to hyperoxia for $60 \mathrm{~h}$, and mean volume $\pm \mathrm{SD}$ was $9.6 \pm 1.7 \mathrm{~mL}(n=7)$. Neonatal rats did not have pleural fluid after $7 \mathrm{~d}$ of hyperoxic exposure. The mortality and BALF protein results suggest that the studies at $60 \mathrm{~h}$ in adults and at $7 \mathrm{~d}$ in neonates were performed after lung injury had occurred.

Lung MPO activities. Lung MPO activities were significantly increased in adult rats after $60 \mathrm{~h}$ of $\mathrm{O}_{2}$ exposure (Fig. 2). In neonatal rats, lung MPO activities did not differ between air and $\mathrm{O}_{2}$ groups after $3 \mathrm{~d}$ of exposure. However, after $7 \mathrm{~d}$, lung MPO was higher in the $\mathrm{O}_{2}$-exposed groups. At $7 \mathrm{~d}$, the lung MPO activity in neonates remained significantly less than that after $60 \mathrm{~h}$ of adult $\mathrm{O}_{2}$ exposure $(p<0.01)$. Lung MPO correlated highly with protein in the BALF $(r=0.713, p<$ 0.005).

Pulmonary histology. No pathologic changes were noted in the sections of the lungs from the air adult group. In the $\mathrm{O}_{2}$ adult group, mild to moderate perivascular and interstitial edema was noted in $3 / 3$ rats, focal alveolar edema in $2 / 3$, and numerous inflammatory cells in the alveolar septae, which were predominantly neutrophils, mixed with fewer numbers of macrophages in $3 / 3$ rats (Fig. $3 A$ ). In addition, $2 / 3$ adult rat lungs showed focal vasculitis, with infiltration of the walls of pulmonary veins by a mixed inflammatory infiltrate consisting of neutrophils and mononuclear cells. Mean scores $( \pm S D)$ for both interstitial and intraalveolar edema and hemorrhage increased significantly in the $\mathrm{O}_{2}$ group (edema: $0.67 \pm 0.82$ for

Table 1. Body and lung weights of neonatal animals*

\begin{tabular}{|c|c|c|c|c|}
\hline & Body weight (g) & Weight gain $(\mathrm{g})$ & Lung weight $(\mathrm{g})$ & $\begin{array}{l}\text { Lung weight } \\
\text { (\% body weight) }\end{array}$ \\
\hline Air, $3 d$ & $9.42 \pm 1.09(2)$ & $3.25 \pm 0.67(9)$ & $0.16 \pm 0.03(9)$ & $1.68 \pm 0.11(9)$ \\
\hline $\mathrm{O}_{2}, 3 \mathrm{~d}$ & $9.28 \pm 0.92(9)$ & $3.06 \pm 0.68(9)$ & $0.15 \pm 0.03(9)$ & $1.57 \pm 0.23(9)$ \\
\hline Air, $7 \mathrm{~d}$ & $19.64 \pm 1.09(16)$ & $12.64 \pm 1.09(16)$ & $0.45 \pm 0.07(12)$ & $2.26 \pm 0.44(12)$ \\
\hline $\mathrm{O}_{2}, 7 \mathrm{~d}$ & $16.02 \pm 2.45(15) \dagger$ & $8.87 \pm 2.55(15) \dagger$ & $0.33 \pm 0.10(14) \dagger$ & $2.05 \pm 0.50(14)$ \\
\hline
\end{tabular}

* Values represent mean \pm SD. Values in parentheses denote $\mathrm{n}$ for each measurement.

$\dagger p<0.05$ for air vs $\mathrm{O}_{2}$ in each age group. 


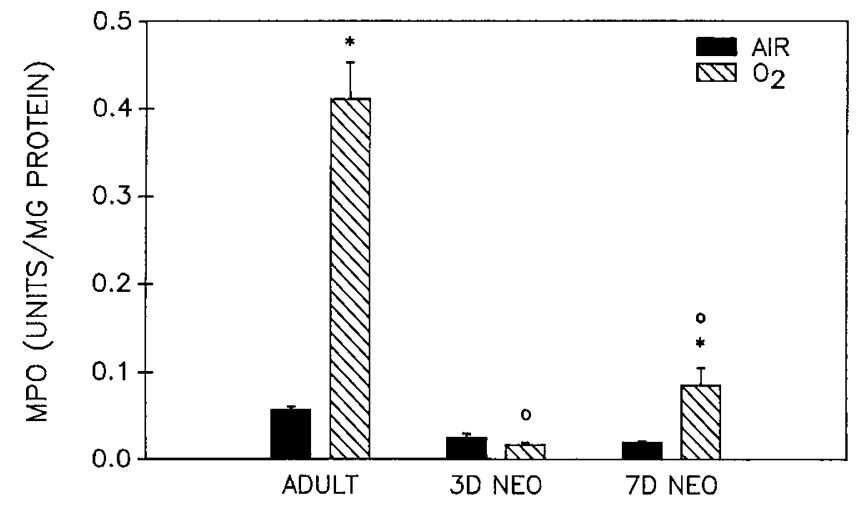

Figure 2. MPO activity in lung homogenates expressed as units/mg protein after exposure of adults for $60 \mathrm{~h}(A D U L T)$ or neonates for $3 \mathrm{~d}(3 D N E O)$ or $7 \mathrm{~d}$ (7D NEO) to air (filled bars) or $\mathrm{O}_{2}$ (hatched bars). Data are expressed as mean \pm SEM; ${ }^{*} p<0.01$ for air $v s \mathrm{O}_{2}$ exposure groups, ${ }^{\circ} p<0.01$ for $\mathrm{O}_{2}$-exposed adults vs neonates; $n=4$ for adult groups, $n=12$ for neonatal groups.

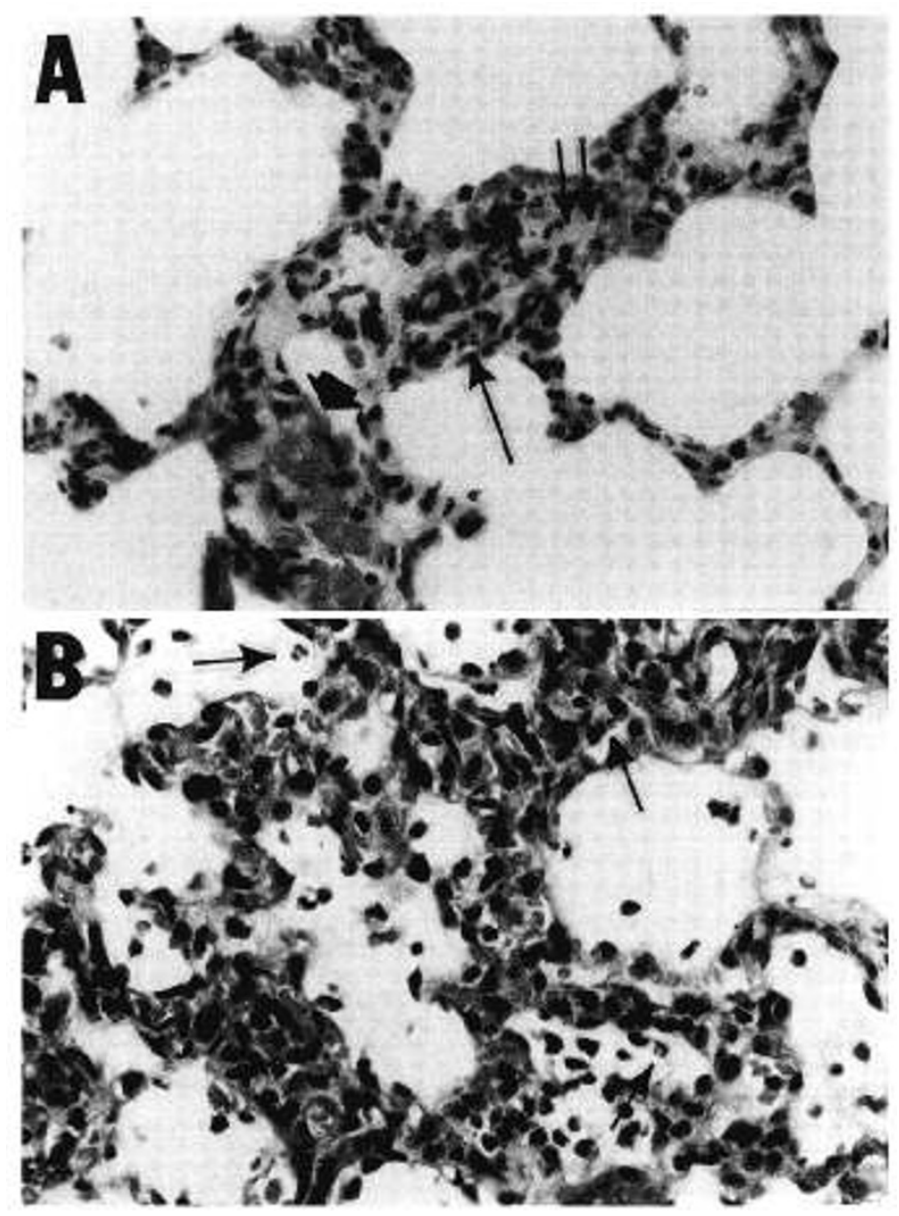

Figure 3. Representative photomicrographs of rat lungs in the $\mathrm{O}_{2}$-exposed groups. (A) Adult lung after exposure to $\mathrm{O}_{2}$ for $60 \mathrm{~h}$ at magnification $\times 400$. The photomicrograph shows hemorrhage (large arrow), interstitial edema (double arrow), and scattered neutrophils in the alveolar septum (small arrow). (B) Photomicrograph of neonatal lung after $\mathrm{O}_{2}$ exposure for $7 \mathrm{~d}$ at magnification $\times 400$ demonstrates alveolar wall hypercellularity. These cells are epithelial and interstitial. Inflammatory cells, consisting of primarily mononuclear cells with scattered neutrophils (arrows), are seen free in the alveolar spaces.

adult air, $3.33 \pm 0.52$ for adult $\mathrm{O}_{2}, p<0.05$; hemorrhage: 0.83 \pm 0.75 for adult air, $3.0 \pm 0.89$ for adult $\mathrm{O}_{2}, p<0.05$ ). The lungs from both 3 -d-old neonatal groups and from the neonates exposed $7 \mathrm{~d}$ to air showed no pathologic changes. The neonatal group exposed to $\mathrm{O}_{2}$ for $7 \mathrm{~d}$ showed mild perivascular edema and hypercellularity of the interstitium and alveolar wall consisting of predominantly epithelial cells and interstitial cells mixed with rare focal neutrophils in $3 / 4$ rats (Fig. $3 B$ ). The lung of one $\mathrm{O}_{2}$-exposed neonatal rat showed focal vasculitis of the small pulmonary vein with infiltration of the wall by a mixed inflammatory infiltrate. Mean scores for both edema and hemorrhage also increased significantly in the 7-d-old neonatal $\mathrm{O}_{2}$ group (edema: $1.33 \pm 1.5$ for neonatal air, $3.0 \pm 0.82$ for neonatal $\mathrm{O}_{2}, p<0.05$; hemorrhage: $2.0 \pm 1.0$ for neonatal air, $3.9 \pm 0.25$ for neonatal $\mathrm{O}_{2}, p<0.05$ ).

Neutrophil counts were taken from two lobes in the lungs of each of four animals in each group. There were no differences in neutrophil counts between air and $\mathrm{O}_{2}$ groups in the 3-d-old neonates (Fig. 4). Total neutrophil counts were higher in the $\mathrm{O}_{2}$-exposed adults and 7-d-old neonates compared with air $(p<0.05)$. However, total counts were lower in the 7-d-old neonatal compared with adult $\mathrm{O}_{2}$-exposed groups $(p<0.05)$, which was analogous to the situation with lung MPO. The percentage of the total count which consisted of neutrophils free in the alveolar air spaces (mean $\pm \mathrm{SD}$ ) and not within or attached to the alveolar septae was $2.0 \pm 3.4 \%$ in adult air, 9.9 $\pm 6.6 \%$ in adult $\mathrm{O}_{2}, 20.2 \pm 7.0 \%$ in 7 -d-old neonatal air, and $49.2 \pm 13.3 \%$ in 7 -d-old neonatal $\mathrm{O}_{2}$-exposed rats. Percentage increased significantly in the neonatal air versus $\mathrm{O}_{2}$ group ( $p<$ 0.05 ). Percentage was also higher in the neonatal versus adult groups exposed to $\mathrm{O}_{2}(p<0.05)$. Percentage of free alveolar neutrophils did not differ in the 3-d-old neonatal exposure groups.

Neutrophils in bronchoalveolar lavage fluid. Lavage recoveries were significantly lower for neonatal groups but did not differ with exposure. Recoveries were $57.7 \%$ and $58.1 \%$ for neonatal air and $\mathrm{O}_{2}$ groups, respectively, and were $72.5 \%$ and $68 \%$ for adult air and $\mathrm{O}_{2}$ groups. Total cell counts in BALF did not differ between air and $\mathrm{O}_{2}$-exposed groups of either age (Fig. 5A). The percentage of the cells which were neutrophils increased significantly in both age groups after $\mathrm{O}_{2}$ exposure

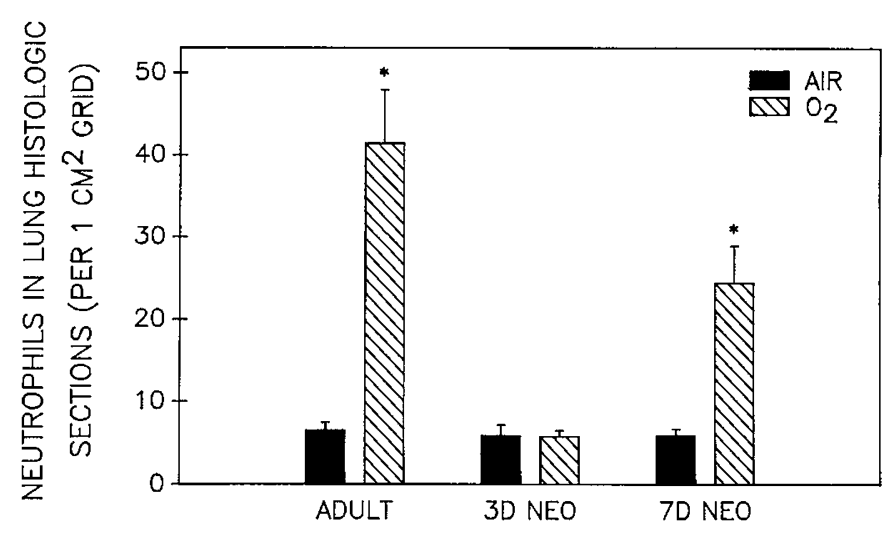

Figure 4. Semiquantitative neutrophil counts in pulmonary histologic specimens per $1-\mathrm{cm}^{2}$ grid at magnification $\times 400$. Specimens were obtained after exposure of adults for $60 \mathrm{~h}(A D U L T)$ or neonates for $3 \mathrm{~d}(3 D N E O)$ or $7 \mathrm{~d}(7 D$ $N E O$ ) to air (filled bars) or $\mathrm{O}_{2}$ (hatched bars). Data are expressed as mean \pm SEM; * $p<0.05$ for air $v s \mathrm{O}_{2}$ exposure groups; $n=3$ for each adult group, $n=$ 4 for each neonatal group. In the $\mathrm{O}_{2}$ exposure groups, adults had higher neutrophil counts than 7-d-old neonates $(p<0.05)$. 

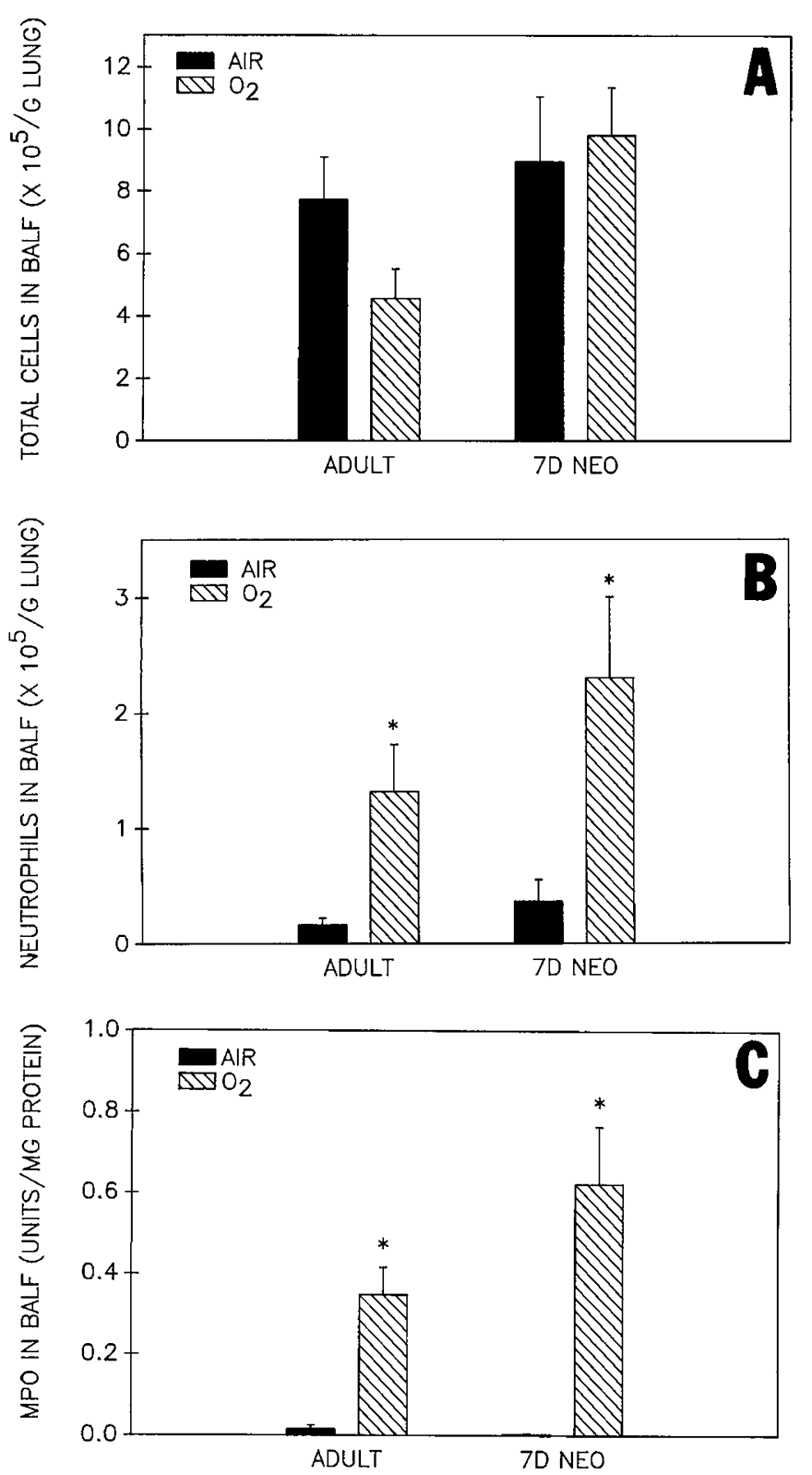

Figure 5. Total cells in BALF expressed as $10^{5} / \mathrm{g}$ of lung weight $(A)$, neutrophil counts expressed as $10^{5} / \mathrm{g}$ of lung weight $(B)$, and MPO activity of the BALF cell pellet expressed as units/mg of protein $(C)$. Measurements were made after exposure of adults for $60 \mathrm{~h}$ (ADULT) or neonates for $7 \mathrm{~d}(7 D N E O)$ to air (filled bars) or $\mathrm{O}_{2}$ (hatched bars). Data are expressed as mean \pm SEM; ${ }^{*} p<0.05$ for air $v s \mathrm{O}_{2}$ exposure groups; $n=4$ for adult groups, $n=8$ for neonatal groups. There were no differences in total cells or total neutrophils in BALF between the adults and neonates within exposure groups.

from $2.03 \pm 1.4 \%$ to $28.25 \pm 5.4 \%$ in the adult and from 2.68 $\pm 0.95 \%$ to $21.56 \pm 4.65 \%$ in the 7 -d-old neonate. Neutrophil counts expressed per $\mathrm{g}$ of lung weight (Fig. $5 B$ ) similarly increased with $\mathrm{O}_{2}$ in each age group. Neutrophil counts did not significantly differ between adult and 7-d-old neonatal groups after $\mathrm{O}_{2}$ exposure, but there was a trend toward higher neutrophils in the BALF of $\mathrm{O}_{2}$-exposed neonates. This is consistent with the histologic findings of increased free alveolar neutrophils in the neonates. MPO activity of the cell pellet in BALF was measured (Fig. 5C) to corroborate BALF neutrophil counts. The correlation of BALF neutrophils and BALF MPO within each sample was $0.887(p<0.005)$. As with lung MPO, neutrophils and MPO in BALF correlated with protein in BALF ( $r$ values of 0.63 and 0.71 , respectively). MPO in BALF was higher in both groups after $\mathrm{O}_{2}$ exposure, but did not differ between adult and neonatal $\mathrm{O}_{2}$-exposed animals. Again, there was a trend toward higher BALF MPO activity in the neonatal $\mathrm{O}_{2}$-exposed groups compared with adults. MPO was also measured in the supernatant of lavage fluid to examine extrusion from neutrophils and was not measurable except in one sample of a neonate after $\mathrm{O}_{2}$ exposure.

Neutrophils in peripheral blood. Neutrophil counts in the blood of air-exposed adult rats were $0.483 \pm 0.11 \times 10^{6} / \mathrm{mL}$ blood $(n=5)$ and increased to $5.4 \pm 1.56 \times 10^{6} / \mathrm{mL}$ blood after $\mathrm{O}_{2}$ exposure $(n=3)\left(p<0.05\right.$, air versus $\left.\mathrm{O}_{2}\right)$. In the 7-d-old neonatal rats, neutrophil counts were $0.57 \pm 0.12 \times$ $10^{6} / \mathrm{mL}$ blood in air $(n=7)$ and $1.26 \pm 0.18 \times 10^{6} / \mathrm{mL}$ blood in $\mathrm{O}_{2}(n=3)$ (NS, air versus $\mathrm{O}_{2}$ ). Blood neutrophil counts were higher in adults compared with neonates in the $\mathrm{O}_{2}$ exposed groups $(p<0.05)$.

\section{DISCUSSION}

We demonstrated a markedly prolonged neonatal survival in hyperoxia compared with that reported in adult rats, as has been previously reported $(2,24)$. However, although neonatal survival was prolonged, mortality was noted after $6 \mathrm{~d}$ and survival was negligible after $14 \mathrm{~d}$ of $\mathrm{O}_{2}$ exposure. Mortality was higher in our group of neonatal rats then has been previously reported (24), which may be related to slight differences in the $\mathrm{O}_{2}$ concentration provided ( $\geq 98 \%$ versus $95 \%$ ). After 60 $\mathrm{h}$ of $\mathrm{O}_{2}$ exposure of adult animals, increased lung weight and BALF protein suggested pulmonary edema, as did the presence of intraalveolar edema histologically. No differences in body growth, lung weight, or histologic edema were noted after 72 $\mathrm{h}$ of $\mathrm{O}_{2}$ exposure of neonatal rats, but after $7 \mathrm{~d}$, there was evidence of significantly delayed body growth and diminished lung weight in the $\mathrm{O}_{2}$-exposed group of neonates. The increased protein in BALF after $7 \mathrm{~d}$ of $\mathrm{O}_{2}$ exposure in the neonates suggests alveolar capillary leak, pulmonary edema, and lung injury.

The pulmonary neutrophil responses of adults and neonates differed. It has been previously reported that neonatal animals have an inflammatory response to hyperoxia $(14,15,25)$, but these studies did not concurrently compare neutrophils in the lungs of adult and neonatal animals. Coalson et al. (26) have reported that premature baboons demonstrate less injury and diminished neutrophils in the alveolar exudate compared with adult baboons after hyperoxic exposure. They did not report comparisons of locations of neutrophils within the lungs. In the present study, there was no increase of lung MPO activity or histologic neutrophil counts after $72 \mathrm{~h}$ of hyperoxia compared with the marked increase in adult lungs after $60 \mathrm{~h}$ of $\mathrm{O}_{2}$. In addition, neutrophil influx into lung tissue appeared not only delayed, but diminished. Both histologic total neutrophil counts and MPO activity in the lung tissue of hyperoxiaexposed neonates at $7 \mathrm{~d}$ were significantly lower than in $\mathrm{O}_{2}$-exposed adults. Although we did not quantitate macrophages in the histologic lung specimens, the increased cells in 
the interstitial area in $\mathrm{O}_{2}$-exposed lungs appeared to be primarily nonspecific interstitial cells, which has been reported by others (27).

MPO is useful for quantitative measurement of neutrophil accumulation in the lung and has previously been shown to be proportional to the number of neutrophils in the lung after injury (21). The present study shows similar trends in lung MPO and pulmonary histologic neutrophil counts in both adults and neonates. Sources of error in lung MPO measurements include release from injured cells (28). We did not detect measurable levels of MPO in the lavage supernatants, although small amounts could have been diluted by the large volume of lavage fluid. Macrophages also contain MPO. Because neutrophils contain 50-150-fold more MPO than macrophages (22, 28), the MPO measurements should be reflective of neutrophil differences. Finally, developmental differences have been found for human neutrophil MPO content with neonatal humans 1-3 wk of age having $50 \%$ of adult MPO/neutrophil (29). In our BALF samples (except for neonatal air samples, whose MPO was below the level of detection of our assay), MPO/mg protein was consistently $25 \%$ of the value for neutrophils $(X$ $10^{5} / \mathrm{mL}$ BALF), suggesting that, at least in BALF, the MPO content for neonates was similar to that of adults.

In addition to differences in timing of neutrophil influx, age-related differences were noted in the distribution of neutrophils in the lungs after $\mathrm{O}_{2}$-induced lung injury. Compared with $\mathrm{O}_{2}$-exposed adults, the 7-d-old $\mathrm{O}_{2}$-exposed neonates demonstrated a significantly higher percentage of cells free in the alveolar space and a trend toward higher neutrophils and MPO in BALF. Compared with neonates, almost all pulmonary neutrophils were within the alveolar tissue in the $\mathrm{O}_{2}$-exposed adults. This enhanced emigration through the alveolar wall may be protective for the neonate. It has previously been reported that adherence to a surface promotes neutrophil activation and respiratory burst (30). It may be that prolonged binding of the neutrophil to the adult alveolar tissue allows more damage.

Several mechanisms could account for our findings of delayed neutrophil entry and diminished retention of neutrophils within the alveolar tissue of neonates. Because neutrophil storage pools are lower in the neonate (31), it is conceivable that the bone marrow of neonates becomes depleted, and further neutrophils cannot be released into the circulation to migrate into the lung. Indeed, our findings that blood neutrophil counts did not increase to the same extent in neonates as adults after $\mathrm{O}_{2}$ exposure suggest that the neonates were unable to mount a circulating neutrophil response equivalent to the adult. Further studies of bone marrow reserves and circulating neutrophils in this inflammatory model are indicated. It is also possible that neonates have enhanced emigration through lung tissue because of differences in release of chemotactic factors, differences in the alveolar/capillary membrane or changes in neutrophil deformability. Neonatal neutrophils have defects of chemotactic function with diminished adherence to cytokinestimulated endothelium and reduced in vitro migration through endothelial monolayers, compared with adult neutrophils (32). Diminished adherence could be due to age-related differences in cell adhesion molecules. Neonatal deficiencies of both of the neutrophil adherence molecules, CD11b/CD18 (Mac-1) and L-selectin, have been documented $(32,33)$. Endothelial and epithelial adherence proteins, such as ICAM-1 and E- and P-selectin, may play a role in neutrophil adherence and movement across the lung after hyperoxia (34). The expression of these adherence proteins in neonatal compared with adult lung is unknown and warrants further investigation.

In summary, the present study corroborates previous reports that neonatal rats have improved tolerance to hyperoxia compared with adults. Neutrophils enter the lungs and alveolar air spaces of both adults and neonates before onset of mortality, but entry is delayed in the neonatal rat. In addition, the pattern of neutrophil migration appears to be different in the age groups, with a greater proportion of neutrophils being retained in the alveolar tissue of adults compared with higher percentages of neutrophils in the alveolar air spaces of neonates. These results suggest that delayed neutrophil migration and/or a difference in the pattern of neutrophil migration may play a role in the increased tolerance of the neonate to hyperoxia. Further study of the role of the neutrophil in neonatal $\mathrm{O}_{2}-$ induced lung injury and of the mechanisms of the differences in neutrophil migration and adherence in neonatal and adult lungs is warranted.

Acknowledgment. The authors thank Freda Purnell for assistance with preparation of the manuscript.

\section{REFERENCES}

1. Frank L, Bucher JR, Roberts RJ 1978 Oxygen toxicity in neonatal and adult animals of various species. J Appl Physiol 45:699-704

2. Yam J, Frank L, Roberts RJ 1978 Oxygen toxicity: comparison of lung biochemical responses in neonatal and adult rats. Pediatr Res 12:115-119

3. Frank L, Sosenko IRS 1987 Prenatal development of lung antioxidant enzymes in four species. J Pediatr 110:106-110

4. Ischiropoulos H, Nadziejko CE, Kumae T, Kikkawa Y 1989 Oxygen tolerance in neonatal rats: role of subcellular superoxide generation. Am J Physiol 257:L411L420

5. Clark JM, Lambertson CJ 1971 Pulmonary oxygen toxicity: a review. Pharmacol Rev 23:37-133

6. Freeman BA, Topolosky MK, Crapo JD 1982 Hyperoxia increases oxygen radical production in rat lung homogenates. Arch Biochem Biophys 216:477-484

7. Barry BE, Crapo JD 1985 Pattern of accumulation of platelets and neutrophils in rat lungs during exposure to $100 \%$ and $85 \%$ oxygen. Am Rev Respir Dis 132:548-555

8. Fox RB, Hoidal JR, Brown DM, Repine JE 1981 Pulmonary inflammation due to oxygen toxicity: involvement of chemotactic factors and polymorphonuclear leukocytes. Am Rev Respir Dis 123:521-525

9. Henson PM, Johnston RB 1987 Tissue injury in inflammation. J Clin Invest 79:669674

10. Hogg JC 1987 Neutrophil kinetics and lung injury. Physiol Rev 67:1249-1295

11. Shasby DM, Fox RB, Harada RN, Repine J 1981 Reduction of the edema of hyperoxic lung injury by granulocyte depletion. J Appl Physiol 52:1237-1244

12. Parrish DA, Mitchell BC, Henson PM, Larsen GL 1984 Pulmonary response of fifth component of complement-sufficient and deficient mice to hyperoxia. $J$ Clin Invest 74:956-965

13. Kubo K, King LS, Kobayashi T, Newman JH 1992 Differing effects of nitrogen mustard and hydroxyurea on lung $\mathrm{O}_{2}$ toxicity in adult sheep. Am Rev Respir Dis 145:13-18

14. Jenkinson SG, Roberts RJ, DeLemos RA, Lawrence RA, Coalson JJ, King RJ, Null DM, Gerstmann DR 1991 Allopurinol-induced effects in premature baboons with respiratory distress syndrome. J Appl Physiol 70:1160-1167

15. Merritt TA, Cochrane CG, Holcomb K, Bohl B, Hallman M, Strayer D, Edwards DK, Gluck L 1983 Elastase and $\alpha_{1}$-proteinase inhibitor activity in tracheal aspirates during respiratory distress syndrome. J Clin Invest 72:656-666

16. Raj JU, Hazinski TA, Bland RD 1985 Oxygen-induced lung microvascular injury in neutropenic rabbits and lambs. J Appl Physiol 58:921-927

17. Smith LJ, Friedman H, Anderson $J 1988$ Hyperoxic lung injury in mice: effect of neutrophil depletion and food deprivation. J Lab Clin Med 111:449-458

18. Boyce NW, Campbell D, Holdsworth SR 1989 Granulocyte independence of pulmonary oxygen toxicity in the rat. Exp Lung Res 15:491-498

19. Anderson DC, Hughes BJ, Smith CW 1981 Abnormal mobility of neonatal polymorphonuclear leukocytes. J Clin Invest 68:863-874 
20. Keeney SE, Mathews MJ, Rassin DK 1993 Antioxidant enzyme responses to hyperoxia in preterm and term rats after prenatal dexamethasone administration. Pediat Res 33:177-180

21. Goldblum SE, Wu KM, Jay M 1985 Lung myeloperoxidase as a measure of pulmonary leukostasis in rabbits. J Appl Physiol 59:1978-1985

22. Krawisz JE, Sharon P, Stenson WF 1984 Quantitative assay for acute intestinal inflammation based on myeloperoxidase activity. Gastroenterology 87:1344-1350

23. Smith PK, Krohn RI, Hermanson GT, Mallia AK, Gartner FH, Provenzano MD, Fujimoto EK, Goeke NM, Olson BJ, Klenk DC 1985 Measurement of protein using bicinchoninic acid. Anal Biochem 150:76-85

24. Frank L 1992 Prenatal dexamethasone treatment improves survival of newborn rats during prolonged high $\mathrm{O}_{2}$ exposure. Pediatr Res 32:215-221

25. Bonikos DS, Bensch KG, Ludwin SK, Northway WH 1975 Oxygen toxicity in the newborn. The effect of prolonged $100 \% \mathrm{O}_{2}$ exposure on the lungs of newborn mice. Lab Invest 32:619-635

26. Coalson JJ, Kuehl TJ, Prihoda TJ, DeLemos RA 1988 Diffuse alveolar damage in the evolution of bronchopulmonary dysplasia in the baboon. Pediatr Res 24:357-366

27. Crapo JD, Marsh-Salin J, Ingram P, Pratt PC 1978 Tolerance and cross-tolerance using $\mathrm{NO}_{2}$ and $\mathrm{O}_{2}$. II. Pulmonary morphology and morphometry. J Appl Physiol 44:370-379

28. Bradley PP, Christensen RD, Rothstein G 1982 Cellular and extracellular myeloperoxidase in pyogenic inflammation. Blood 60:618-622

29. Christensen RD, Rothstein G 1985 Neutrophil myeloperoxidase concentration: changes with development and during bacterial infection. Pediatr Res 19:1278-1282

30. Nathan CF 1987 Neutrophil activation on biological surfaces. J Clin Invest 80:1550 1560

31. Erdman SH, Christensen RD, Bradley PP, Rothstein G 1982 The supply and release of storage neutrophils: a developmental study. Biol Neonate 41:132-136

32. Anderson DC, Rothlein R, Martin SD, Krater SS, Smith CW 1990 Impaired transendothelial migration by neonatal neutrophils: abnormalities of Mac-1 (CD1 Ib/CD18)dependent adherence reactions. Blood 76:2613-2621

33. Anderson DC, Abbassi O, Kishimoto TK, McIntire LV, Smith CW 1991 Diminished human MEL-14 antigen on neonatal neutrophils underlies impaired CD11/CD18independent adhesion to endothelial cells. Pediatr Res 27:153A

34. Pilewski JM, Albeida SM 1993 Adhesion molecules in the lung: an overview. Am Rev Respir Dis 148:S31-S37 